\title{
Optimal Control in Manufacturing Areas Increase the Productivity in the Aerospace Industry of Mexicali, Baja California, México
}

\author{
Rogelio Lopez Rodríguez, Juan Carlos Quiroz Sánchez, Alicia Lopez Ortiz, Juan Gabriel Lopez, \\ Olivia Yessenia Vargas Bernal
}

\begin{abstract}
The efficient control in the manufacturing control is very essential to increase the productivity and some specialized devices are made with and adequate functions. These devices are MEMS (Micro Electromechanical Systems), which are low-power microdevices widely used in the industrial processes of the Mexicali aerospace industry, which have the function of controlling the operation of industrial systems at any stage of manufacturing by evaluating the way to carry out their activities, comparing standardized values with data real and activate and deactivate high power actuator mechanisms such as fans, motors, electric pumps and other high power used in this installed industry. These microdevices have specific characteristics in their operation to obtain the best operational performance of industrial equipment and machines, at a low cost and partially operating according to the operating system reference values of industrial systems and generating a safe process in their operation. The industrial processes of the Mexicali aerospace industry require specialized knowledge because they manufacture components with very rigid operations because they are manufactured for aircraft with very rigorous regulations, due to the high security that air transport requires. MEMS have increased their use in the last ten years, where it has been applied to various industries due to the simple way of coupling with industrial systems, and this is why research was conducted to evaluate its use in a company in this city that they did not intend to use them and when observing that they increased their productive performance at one stage of their industrial processes, they chose to apply them in all their manufacturing areas. The investigation was from 2018 to 2019.
\end{abstract}

Keywords: MEMS, productive performance, aerospace industry, industrial manufacturing.

Manuscript received on 03 April 2021 | Revised Manuscript received on 09 April 2021 | Manuscript Accepted on 15 April 2021 | Manuscript published on 30 April 2021.

* Correspondence Author

Rogelio Lopez Rodríguez *, Tronco Común, Facultad de Ingeniería y Negocios San Quintín, Universidad Autonoma de Baja California, San Quintín, Baja California, Mexico, Email: Rogelio.lopez.rodriguez@uabc.edu.mx

Juan Carlos Quiroz Sánchez, Departamento de Ciencias Básicas, Facultad de Ingeniería, Universidad Autonoma de Baja California, Mexicali, Baja California, Mexico, Email: quiroz.juan@uabc.edu.mx.

Alicia Lopez Ortiz, Coordinadora en Fisioterapia, Universidad Autonoma de Durango, Mexicali, Baja California, Mexico, Email: alicialopezortiz90@gmail.com

Juan Gabriel López Hernández, Departamento de Computación, Instituto de Ingeniería, Universidad Autonoma de Baja California, Mexicali, Baja California, Mexico, Email: glopez17@uabc.edu.mx

Olivia Yessenia Vargas Bernal, Departamento de Ingeniería Industrial, Facultad de Ingeniería, Universidad Autonoma de Baja California, Mexicali, Baja California, Mexico, Email: olivia.yessenia.vargas.bernal@uabc.edu.mx

(c) The Authors. Published by Lattice Science Publication (LSP). This is an open access article under the CC-BY-NC-ND license (http://creativecommons.org/licenses/by-nc-nd/4.0/)

\section{INTRODUCTION}

MEMS have revolutionized technology in the aerospace industry by being used as control systems in manufacturing areas, with microlevel electromechanical systems coupled with industrial processes to control high power industrial equipment and machinery ${ }^{1}$. These microsystems made activities of installation and gluing of electronic components in electronic boards used for the operation of the autopilot in the evaluated industry. In addition to these functions, MEMS can verify standardized reference values and compare them with real data, to check that the operation of manufactured products operate efficiently, elaborating the shutdown activity to stop equipment operations and industrial machinery when it is required to verify in detail any situation outside the functional characteristics of the manufactured articles $^{2}$. Likewise, MEMS can perform the ignition function to continue monitoring production. Figure 1 shows illustrations of MEMS, observing in $1 \mathrm{~A}$ a microconnection and $1 \mathrm{~B}$ several electronic micro-racks where MEMS are installed and connected. Figure 1 represents a 10 micron view of a microconnection and electronic microdrives of a MEMS used in a stage of a production line in the aerospace industry analyzed, observing that Figure 1A illustrates two sections of electrical connection in good condition, indicating that the micro system is working optimally and in figure $1 \mathrm{~B}$, several electronic boards are shown (segmented by squares), showing in the central part of each box the connection place for two MEMS. This microanalysis was developed to adequately know the operability of the microsystems and to evaluate the productivity and determine if it was necessary to elaborate any adjustment in the micro-connections of the MEMS or in the microtableros and quickly make the required modifications. It is noted that the tuning process with the microsystems was developed in a company that develops specialized microscope electronic microcircuits ${ }^{3}$.

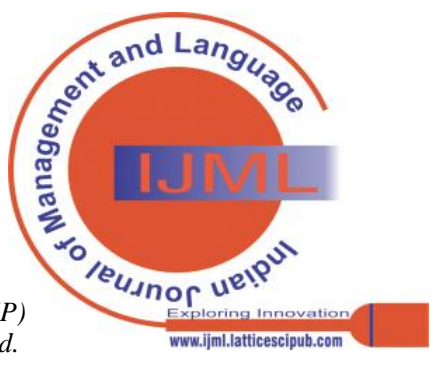




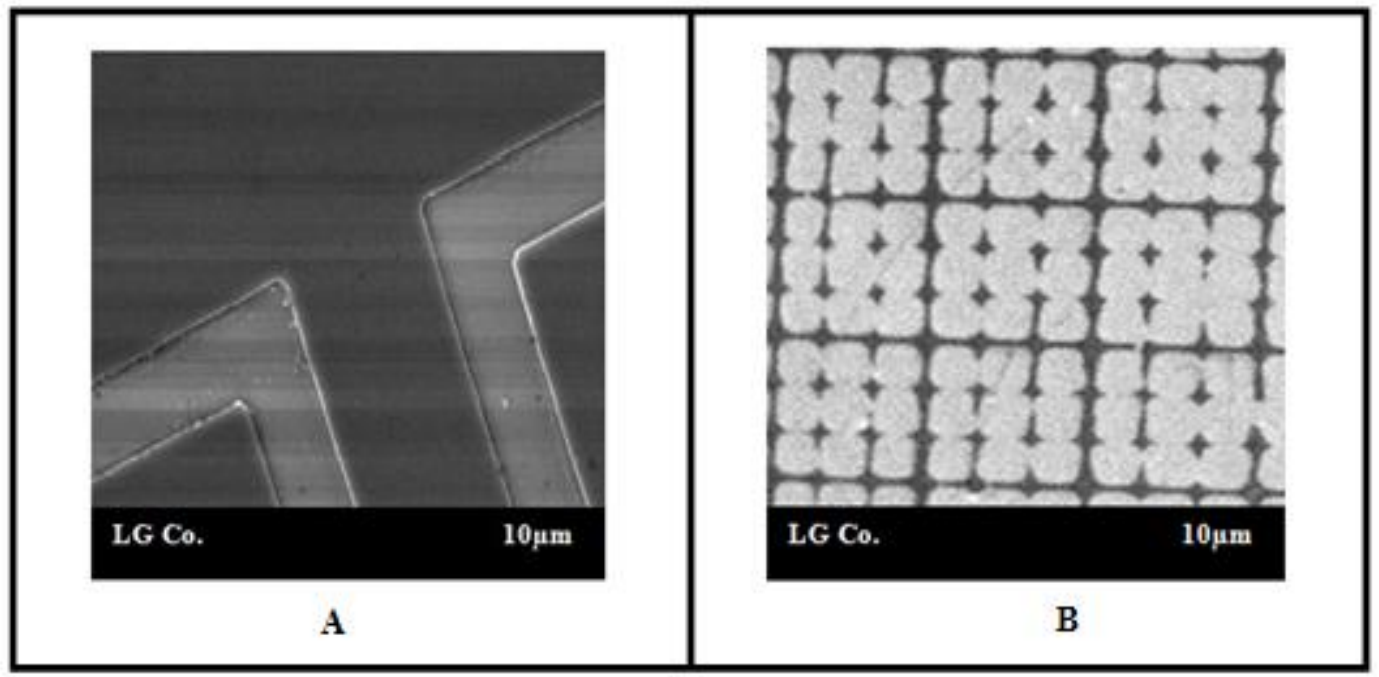

Fig. 1. Microscopic view of MEMS: (A) Microconexions and (B) Electronic microboards to MEMS (10X)

\section{Importance of using MEMS}

MEMS technology has been a very relevant topic since the beginning of the 21st century to optimize activities in the manufacturing areas, being very useful for controlling various operations, where every day the industries have the objective of improving the efficiency of manufactured products and industrial processes, having these micro systems in small spaces and reducing the sizes of equipment and industrial machinery ${ }^{4}$. With MEMS they are applied in all types of industries and in aerospace it is no exception, where they are used in various systems The investigation made in an aerospace industry was an analysis of the use of these micro systems to improve the operability of equipment and machinery industrial and quickly and effectively evaluate the main operating characteristics of manufactured products, being evaluated with electronic transmission-reception sensors, optical and electrical and electromechanical. The study elaborated was relevant in modern society because it improves the interaction between the manufacturer and the consumer, which ensures the reliability of manufactured products, generating benefits for the manufacturer and the customer ${ }^{5}$.

\section{Origin of electromechanical microsystems}

The main objective of MEMS manufacturing was to evolve technologies that sought to miniaturize simple and complex industrial systems and that operated in smaller areas, saving space in industries by having small and not large buildings that generated higher construction or rental costs. to reduce operating costs. MEMS integrate multiple functions in a microelectronic device ${ }^{6}$. The term MEMS was developed in the United States at the beginning of the 21st century and in Europe it became known as micro technological systems (MST), and today MEMS has become increasingly prevalent throughout the world with this terminology. Experts on this topic agree that MEMS had its beginning when developing semiconductors, based on the manufacture of transistor in Bell laboratories, developed by scientists Shockley, Bardeen and Brattain in 1947. This evolved the technology of that time in especially the area of electronics to create devices with greater capacity, speed and operational functionality, smaller and at lower cost, accelerating technological development in the 21st century ${ }^{7}$.
At the beginning, it was difficult to connect the electronic microcomponents because the reduced space caused their microconnections to be very close and joined at the time of manufacture, so it caused short circuit and interference between them when operating.

\section{MEMS operational efficiency}

The development of these microsystems has revolutionized the technology of electronics, only it has had its limitations with respect to its application due to a lack of knowledge and willingness to be used by the management and supervisory personnel of the various types of industries, in addition of not having the manufacturing and testing technology, which generates a higher cost when requesting them from the MEMS developers with the required specifications ${ }^{8}$. There are some industries worldwide, which have in their facilities the way to manufacture them and specialized personnel for the preparation of tests and support when used in their industrial processes, being innovative companies that have had great growth in a short time due to use MEMS as control microdevices ${ }^{9}$. The first electromechanical microsystems were developed for microsensors, generating the great discovery of piezoelectricity activity, obtained from the union of silicon with germanium to manufacture the pressure sensor, being a novelty at the time of its manufacture and currently with great variety of functions in industries and other activities. In addition to using silicon, the scientists who created MEMS began to develop other experiments with other types of materials to be applied not only to products manufactured in the electronic industry, but in other industries such as aerospace, agriculture, food and beverages, automotive, biomedical, ceramics, metalworking, plastics, telecommunications and textiles ${ }^{10,11}$.

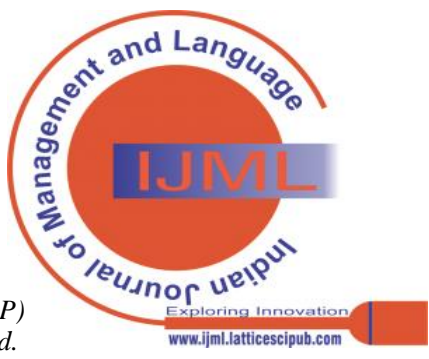




\section{Evolution of MEMS}

After the MEMS were created a little before 1950 with experiments made mainly with silicon material and the creation of the piezoresistive micro sensor in 1953 and semiconductor strain gauges in 1957, the development of other microdevices was accelerated as solid state microtransducers and micro-actuators for strategic functions in various industries ${ }^{12}$. Once the operation of the piezoresistive sensor was understood, the pressure sensor was manufactured in the 1960s, which is widely used today; microtransducers after 1970, micro-actuators in the 1980s, micro-mechanisms and micromotors between 1987 and 1989 , and from that date to the present day the creation of microsystems, leading to the development of MEMS with the manufacture of micro-robot micromachines ${ }^{13,14}$. All the technology developed after 1970, was due to the operation of microtransducers and micro-actuators and it was in 1987 when the term MEMS was created after three meetings, one held in Salt Lake, Utah, another in Hyannis, Massachusetts and the last one in Princeton, New Jersey, so that academics and experts on the subject named it with this term, being pioneers in this type of technology. Currently MEMS are used in used as an interdisciplinary factor of knowledge used in countless areas of science and engineering, for the solution of problematic situations, largely linked to control engineering ${ }^{15}$.

\section{Manufacturing Features}

The manufacture of MEMS requires three important stages for its optimal functionality, each one being explained immediately ${ }^{15}$.

a) Miniaturization. The goal is to make very small devices on a microscopic scale with very short response times.

b) Multiplicity. It generates very efficient operations to manufacture a large quantity of articles in a short time.

c) Microelectronics. It consists of coupling specialized electronic components in an optimal way to efficiently carry out industrial operations.

These characteristics determine the way of operating the MEMS based on the required needs, being of great relevance in the manufacturing areas of the aerospace industry. One of the important aspects is that not all electronic components, even miniaturized, can be coupled due to their operating specifications.

\section{Control systems}

They are devices and equipment that have the ability to manipulate actions of activities in manufacturing areas. It is composed of several elements that interact with each other to perform the appropriate functions in industrial operations, with the aim of obtaining a desired result. They exist of open, isolated and closed type and with feedback ${ }^{5}$. The control systems operate based on certain regulations, obtaining numerical information of the evaluated variables and preparing the necessary control with a comparative process of standardized values. These systems control actuators, generating activation and deactivation functions at the indicated times for optimal operation of industrial equipment and machinery ${ }^{16}$. Control systems in electronic devices can be simple or complex, depending on what you want to manipulate, to be evaluated based on their functionality, designed and manufactured with basic components such as coils, capacitors, relays, resistors and low-power transistors that control high power actuators that generate high effort activities required in the analyzed production line. This activity gives great support to the manufacturing areas generating great savings.

\subsection{Innovations with MEMS}

MEMS have been the devices that have generated great importance in the last ten years, which is why many industries have decided to use them in a great many industrial processes. In addition, educational institutions have chosen to teach topics related to electromechanical microsystems, preparing experimental tests for application in various areas of engineering. This is done to control having a constant inspection of features or activities that equipment cannot control $^{17,18}$.

\section{METHODOLOGY}

An investigation in an aerospace industry in the city of Mexicali, with four steps was made to improve the control of certain steps in the manufacturing areas. The steps developed are explained below:

Step 1. A correlation analysis of operative efficacy and operability and workers, e yielding of industrial equipment and machinery and workers, in a production line 1 of the automatic and manual insertion area of an aerospace industry installed in Mexicali, where electronic micro-drums used in the autopilot system of commercial aircrafts are manufactured.

Step 2. A correlation analysis of productivity and quality was made to evaluate the situations in the initial time without use MEMS and after utilized MEMS, obtained comparative evaluations.

Step 3. Was made a mathematical simulation with the Simulink of MatLab ${ }^{17}$ used to design MEMS developed to control the operation of an industrial machine for surface installation and assembly of electronic microcomponents, to control activation and deactivation times to support savings in energy consumption and expenses production.

Step 4. Once the optimal operation of the MEMS of the previous step had been determined, two MEMS were created, being for a functional characteristics review team analyzing current and voltage values of the autopilot devices and comparing them with standards reference.

The use of MEMS in the industrial processes of any type of industry is of great importance because it has greatly helped to increase the production, quality and productivity indices. Based on this, statistical evaluations are made with the MatLab program ${ }^{18}$.

\section{RESULTS}

The evaluations prepared reflected the conditions in which the industrial process operated, where the goals proposed by the management area were not achieved. This occurred due to the lack of control when not using the MEMS.

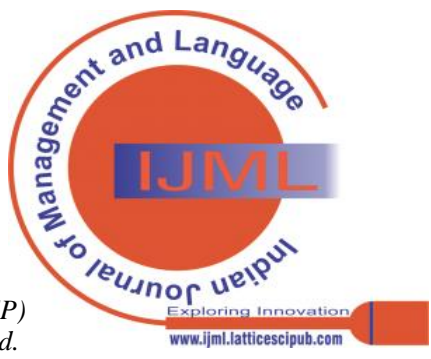


Once the electromechanical microsystems began to be used, both the industrial equipment and machinery and the workers increased the operating levels, and with this the productivity indices that kept the management and supervisory personnel concerned.

\section{Correlation of operability and operational efficiency}

The operability of the industrial equipment and machinery together with that of the workers is an adequate indicator that reflects the way in which the activities in the evaluated aerospace industry were carried out. Before using the electromechanical microsystems, there was not a total control of all the stages in the industrial processes, so that in some areas of the manufacturing areas, unfinished products were observed, generating incomplete inventories and with it unnecessary storage costs. Figures 2 and 3 show a correlation of indices of the operating efficiency of industrial equipment and machinery and of workers, being an important factor in achieving the proposed goals in various hourly, daily, weekly, monthly, seasonal and annual periods. In figure 2 belonging to the month of June 2018, the number of workers that it was necessary to require to prepare manual operations that later with the use of MEMS is observed, being 90 people in line 1 that was evaluated in this investigation, where a large part of these personnel sometimes did not carry out any activity because the management and supervision personnel commented that this amount was necessary as an emergency worker to replace some workers when they felt tired or were not in adequate conditions to carry out their functions in a manner Optimal for the health aspect or for some other situation that complicates the operational performance of the workers. Regarding the quantity of equipment and machinery it was 10 as a whole and in operational efficiency, indices are presented with a maximum of $60 \%$, indicating that there were not optimal productivity indices, as they did not have a good use of the equipment and industrial machinery and workers of line 1 analyzed.

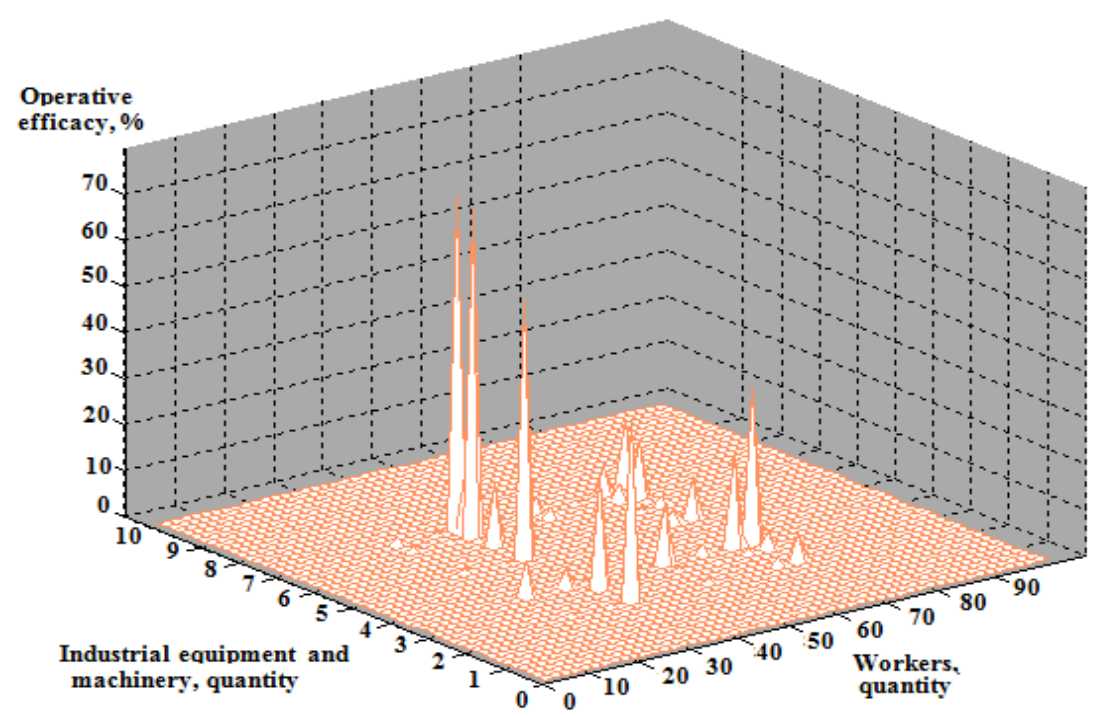

Fig. 2. Correlation of indices of operational efficiency and operational performance of industrial equipment and machinery and workers (June 2018)

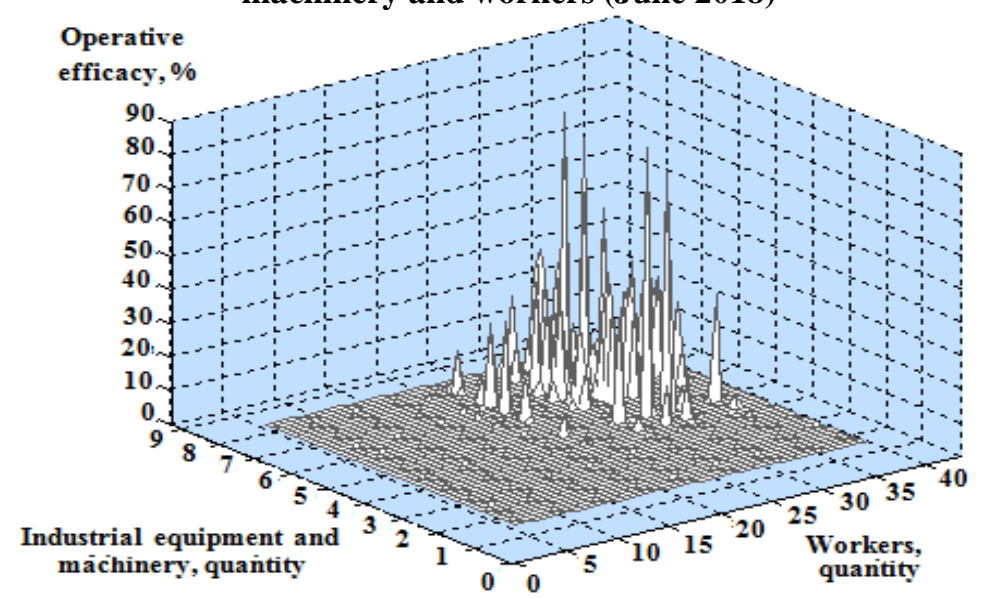

Fig. 3. Correlation of indices of operational efficiency and operational performance of industrial equipment and machinery and workers (June 2019)

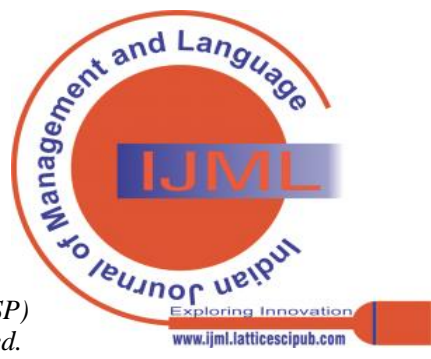


After evaluating the situation of the evaluated manufacturing area, it was determined to use the electromechanical microsystems to improve productivity levels as represented in Figure 3, indicating that it is from the month of June 2019. The evaluations were in the months of June that It is when this aerospace industry had its maximum operational performance in both industrial equipment and machinery and in workers. This figure shows that the number of workers decreased to 40, relocating the rest of the 90s and generating savings in production costs. This occurred. MEMS developed industrial operations control processes, reducing the workforce and increasing automation activities. The relocated workers developed functions in a new production line, which was necessary to start operations of a new product, increasing the competitiveness of the evaluated industry. The amount of equipment and machinery was reduced from 10 to 9, saving on electricity consumption and operating efficiency increased to nearly $80 \%$.

\section{Productivity and quality correlation}

Figures 4 and 5 illustrate the productivity indices, indicating levels of up to about $75 \%$ for the month of June 2018, production levels close to 6,000 products manufactured in this analyzed month and quality indices close to $50 \%$. This is because there were various manual activities that generated a large number of errors, decreasing production levels. This was due to the lack of control at each stage in an optimal way, being a situation that concerned management and supervisory personnel, which required an investigation supported by expert investigators

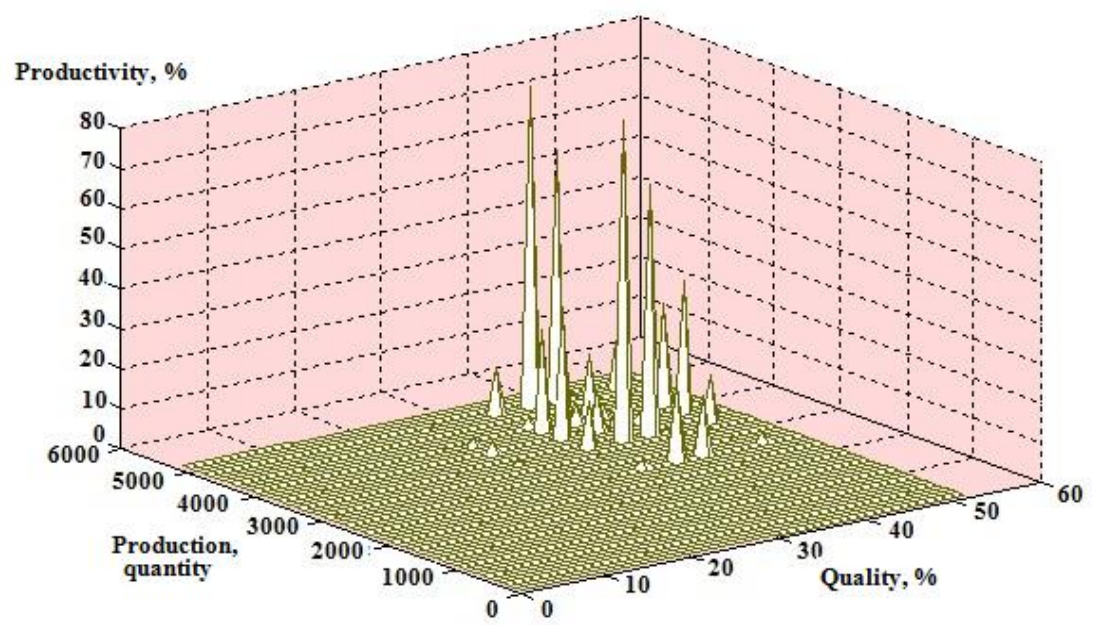

Fig. 4. Correlation of productivity and quality levels (June 2018).

In a large majority of industries of any type, managers and supervisors of industrial processes at each stage of manufacturing areas focus on the main production activities, and the concentration is so high that they do not generate improvements and continue to eject operations as a customary process, even observing that there were human and industrial equipment and machinery errors. In addition, they learned that unfinished products were stored due to the generation of errors, causing extra production costs. Figure 5 illustrates productivity levels close to $80 \%$, increasing this factor by $5 \%$, in addition to quantities of manufactured products close to 9000 and with quality indices of $85 \%$.

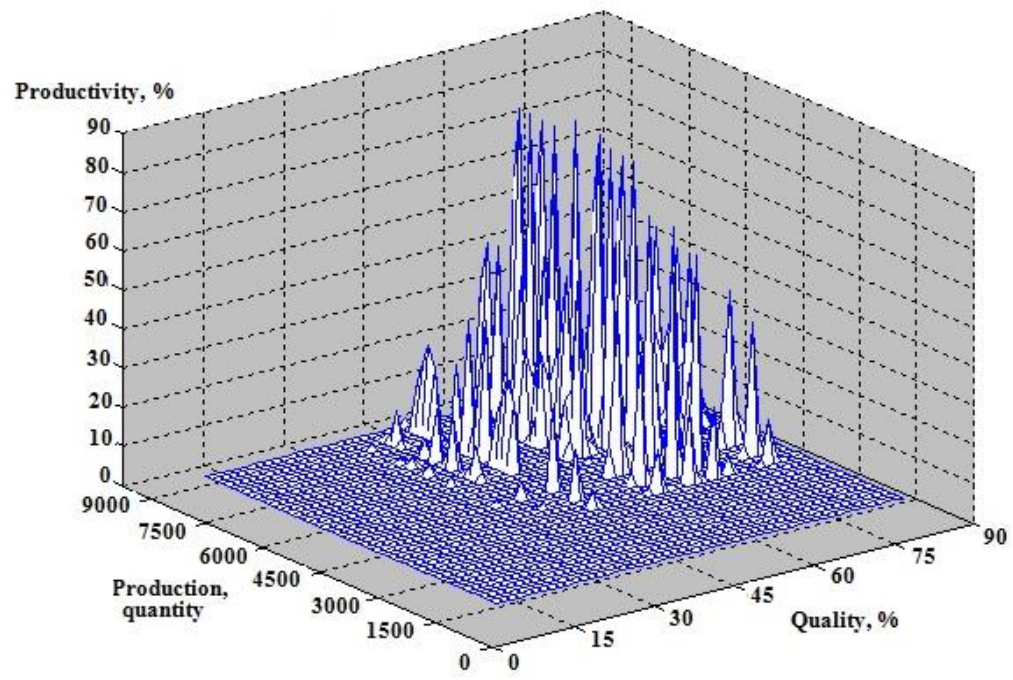

Fig. 5. Correlation of productivity and quality levels (June 2019).

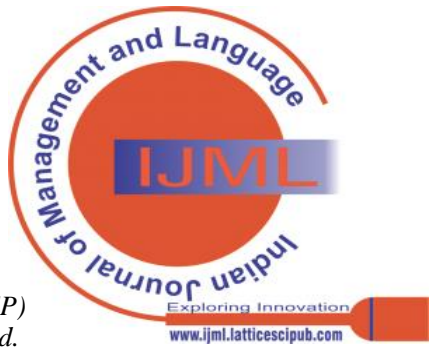




\section{Microanalysis of MEMS connections}

One of the important aspects to achieve the optimal functionality of the MEMS was the microclimate control, with which these microsystems that developed the functions of control of industrial operations could be kept operating in good condition. In figure 6 , a micro-micron analysis is shown, where small dust spots are observed, without being relevant to the functionality of MEMS. By other way, was necessary have micro-connections as clean as possible without the presence of agents that disturb their operation was due, in particular, to the industry being evaluated. I implement the placement of specialized filters to avoid the presence of contaminating agents, as well as dust or microorganisms, in addition to temperature and relative humidity control. . The lifetime estimate with optimal MEMS functionality was five years, without generating failures. The period of this microanalysis was one year.

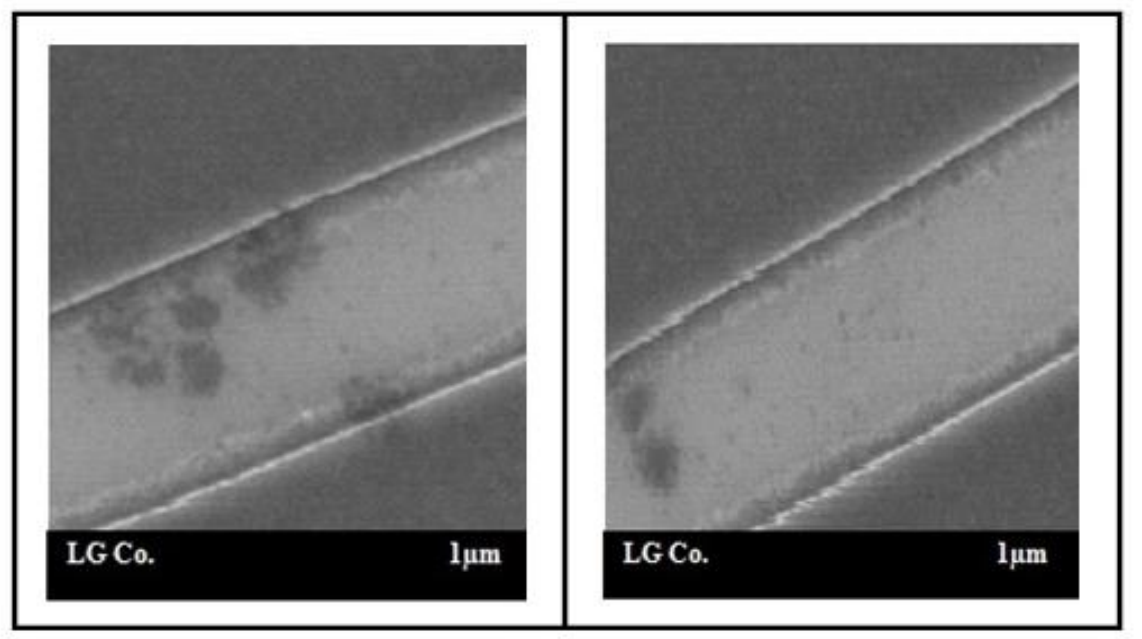

Fig. 6. MEMS microconnections dirty by dust from the interior of the evaluated industry

\section{CONCLUSIONS}

The use of MEMS has generated expectations for the development of new technologies and innovation, increasing productivity, quality, and improving the operational efficiency of industrial equipment and machinery and of workers in manufacturing areas. These microsystems have supported the solution of problematic situations in various applications, where they have contributed to improving the living conditions of the populations, in addition to security aspects, such as the case of this research with the manufacture of electronic microsystems controlled by MEMS for the automatic pilot of a commercial aircraft. In addition, in the area of medicine, they have helped save lives with electromechanical microsystems implanted in the body or ingested to solve a health symptom. MEMS technology has created new opportunities in industries, being a great example of a solution from a different perspective, offering safer, more efficient and economic solutions, with reduced spaces and the development of new industrial processes and products. This investigation was made in an aerospace industry in the city of Mexicali, was very relevant, observing that the productivity, quality, operability and safety indices were increased in the industrial processes evaluated in order to replicate the study throughout the company in all manufacturing areas.

\section{ACKNOWLEDGEMENTS}

The researchers are grateful for the support to the company where the investigation was made, which was elaborated without financial funds, and only with the economical and infrastructure of the participating agricultural industry and the educational institutions.

\section{REFERENCES}

1. Christian C Hindrichsen, Ninia S Almind and Simon H Brodersen (2010) "Triaxial MEM accelerometer with screen printed PZT thick film”, 108-115; Journal of Electroceramics 25 (2-4), 35-46. [CrossRef]

2. Dickson, W.C.; Yee, T.K.; Coward, J.F.; McClaren, A.; Pechner, D.A. (2013) "Compact fiber optic gyroscopes for platform stabilization", In Proceedings of the SPIE 8876, Nanophotonics and Macrophotonics for Space Environments VII, 88760L, San Diego, CA, USA, 21-25. [CrossRef]

3. Gastone C. Leonardo R, Arlanna M, Paolo D,(2015) "MEMS sensor technologies for human centred application in health care, physical activities, safety and environmental sensing: A review on research activities in Italy", Sensors (Basel), March 2015, 15 (3), 6441-6468. [CrossRef]

4. Gustavo López Badilla, Benjamin Valdez Salas, Michael Schorr Wiener. (2012). Book Bookchapter Microscopy and spectroscopy analysis of MEMS corrosion used in the electronics industry of Baja California region, Mexico, Chapter 9, INTECH, Quality New Perspective, Ed. Gustavo López Badilla, Benjamin Valdez Salas, Michael Schorr Wiener, PP. 326. [CrossRef]

5. G. Lopez, A. Vega, D. Millan, J. Gonzalez, and G. Contreras (2012) Effect of Corrosion on Control Systems in the Electronis Industry of Mexico, Ingeniería. Investigación y Tecnología ISSN: 1405-7743, vol. XIII, núm. 4, octubre-diciembre, 2012, pp. 461-472. [CrossRef]

6. Jasón Clark (2018) "Self-Calibration and performance control of MEMS with applications for IoT”, Sensors, 18 (12), 4411. [CrossRef]

7. 7. Jin Tian, Wenshg Yang, Shenming Peng, Tao Tang, Zhijun Li (2016) "Application of MEMS accelerometers and gyroscopes in fast-steering mirror control systems", Sensors Journal, 16 (4), 440. [CrossRef]

8. López-Badilla, Gustavo; González-Hernández, Catalina; Valdez-Ceballos, Antonio Análisis de corrosión en MEM de la industria electrónica en ambientes árido y marino del noroeste de México Científica, vol. 15, núm. 3, julio-septiembre, 2011, pp. 145-150.

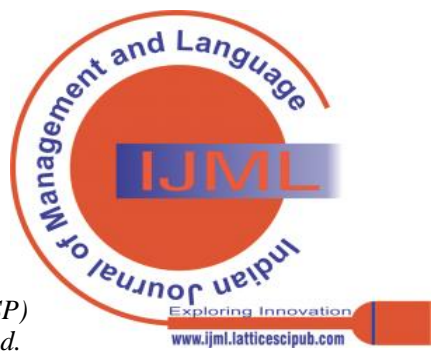


9. Matthew T, Tal C (2009) Photonic Micro-Electromechanical Systems Vibrating at X-band (11-GHz) Rates Phys. Rev. Letter, 102, 113601 Published 19 March 2009, 3(1), 43-58.

10. Prakash, G.; Raman, A.; Rhoads, J.; Reifenberger, R.G. Parametric noise squeezing and parametric resonance of microcantilevers in air and liquid environments. Rev. Sci. Instrum. 2012, 83, 065109, 1-21. [CrossRef]

11. Prathish B, Joseph R, Sumangala K, Kavitha S (2017) Multiresonant Frequency Piezoelectric Energy Harvesters Integrated with High Sensitivity Piezoelectric Accelerometer for Bridge Health Monitoring Applications, Smart Materials Research Journal, Research Article Open Access, Volume 2017, Article ID 6084309, 1-23. [CrossRef]

12. Roger Allan; "MEMS and Nano Push for Higher System Integration Levels", Electronic Design, 58 (1), 777; 2010.

13. Sergey Edward Lyshevski (2005) "Book Nano and Micro Electromechanical systems. Fundamentals of nano and microengineering", CRC Press, 978-0-8493-2838-1, Second Edition, 15.

14. Stepan Lucyszyn, Suneat Pranonsatit, Stepan Lucyszyn, Suneat Pranonsatit (2013). "RF MEMS for antenna application", 2013 7th European Conference on Antennas and Propagation (EuCAP), IEEE Explore.

15. Tuite Don, (2009) "Motion-Sensing MEMS Gyros And Accelerometers Are Everywhere", Mc Graw Hill Ed.

16. Villanueva L, Bausell, J, Brugger, (2016) Grand Challenge in N/MEMS. Frontiers in Mechanical Engineering, 1-16. [CrossRef]

17. Zawada Tomas, Lou-Moeller Rass, Hansen Karsten (2010) "High coupling piezoelectric thick film materials for MEMS-based energy harvesting devices", In Energy Harvesting Storage Conference Munich.

18. Walsh Azarm, Balachandran Magrab, Herold Duncan (2010) "Engineers Guide to MATLAB", Prentice Hall, ISBN-10: 0131991108.

\section{AUTHORS PROFILE}

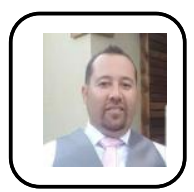

Rogelio Lopez Rodríguez, is a professor and researcher in the Universidad Autonoma de Baja California (UABC) and studied Computing, and then studied a Master of Information and Communication Technologies, and finally is in the process of obtaining her Ph.D. in Education. Specialty Applied leadership for renawable energy and energy efficiency program. "Programa aplicado a liderazgo de energías renovables y eficiencia energética"HARVARD T.H.CHAN, SCHOOL OF PUBLIC HEALTH, Center for health and the global environment $\mathrm{He}$ has participated in two publications one in Dispositivo automatizado para control de micro corrosión generada en convertidor de ozono instalado en área de producción de industria aeroespacial de Mexicali, with more than 12 years in education sector and research. He has experience in computing laboratory activities to apply improvement tools and techniques he is a university degree profesor of computing engineer industrial and environmental engineering from more than 12 years ago in Instituto Tecnologico de Ensenada (TECNM). He has participated in renewable energy activities in Harvard T.H. CHAN ,and I publish his work in the same university with the name of SISTEMA DE TRANFORMACION DE ENERGIA TERMOSOLOAR SUSTENTABLE

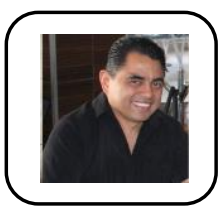

Juan Carlos Quiroz Sánchez, received the B.S. degree in Physics and Mathematics from the National Polytechnic Institute, Mexico, in 2000, the M.S. degree in electronic engineering from the University of Baja California, Mexico, in 2011, received the P.h.D. degree in science in the Institute of Engineering of the University of Baja California. His research interests include optical properties of semiconductors materials for photovoltaic applications and devices simulation "OPTIMIZATION OF ORGANIC PHOTOVOLTAIC DEVICE PERFORMANCE VIA EXCITON GENERATION PROFILE ADJUSTMENT". He has carried out research on ergonomic activities in industrial processes "THE NEGATIVE EFFECTS OF DISCOMFORT AND PAIN IN WORKERS OF A METALLIC INDUSTRY OF MEXICALI, MEXICO”. He has conducted research to evaluate some methods and techniques to improve workers' working conditions, and to work with Notch sensors on some parts of people's bodies to measure the characteristics of movements when workers perform functions in industrial processes. "EVALUATION OF ERGONOMIC CONDITIONS WITH NOTCH SENSOR USED IN THE ELECTRONICS INDUSTRY OF MEXICALI, MEXICO". He is a professor in the Autonomous University of Baja California (UABC) from more than 10 years ago. He has given lectures in various areas of physics and its application.

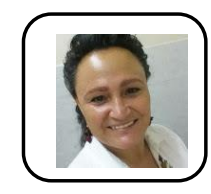

Alicia Lopez Ortiz, is professor with degree in Physical Therapy and Rehabilitation with a Master's Degree in Physical Education and School Sports. She worked supporting education on health issues in rural communities in B.C. Mexico. It remains active providing consultations for both Physiotherapy and Alternative Therapies for more than 25 years. Teacher in the Bachelor of Physiotherapy for 10 years. She participated in the research "EFFECT OF A PHYSIOTHERAPEUTIC INTERVENTION ON THE KINEMATICS OF THE KNEE IN GIRLS WITH FEMORAL ANTEVERSION". She has carried out research on ergonomic activities in industrial processes "THE NEGATIVE EFFECTS OF DISCOMFORT AND PAIN IN WORKERS OF A METALLIC INDUSTRY OF MEXICALI, MEXICO". She collaborated to in the investigation "EVALUATION OF ERGONOMIC CONDITIONS WITH NOTCH SENSOR USED IN THE ELECTRONICS INDUSTRY OF MEXICALI, MEXICO". Currently Academic Coordinator in Physiotherapy at the Autonomous University of Durango, in Mexicali, B.C., Mexico.

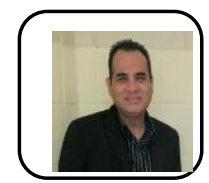

Juan Gabriel Lopes Hernández, is a professor and researcher in the Autonomous University of Baja California (UABC) and studied Industrial Engineering, and then studied a Master of Computer Science, and finally is in the process of obtaining her Ph.D. in Science. He has participated in two publications in Software Development and manufacturing, with more than 10 years in industrial sector research in industrial processes, evaluating manufacturing, environmental and sustainable issues. He has experience in laboratory activities to apply improvement tools and techniques and methods to reduce defective products manufactured in the electronics industry. He is university degree professor of industrial and environmental engineering from more than 10 years ago. He has participated in ergonomic activities in industrial processes to I prove the working conditions of automated and operations, and to analyze the behavior of workers and supervisors and managers to determine the good interrelation in work activities to obtain the maximum effectiveness of performance issues operational and productivity and quality. He has also participated in conference presentations and book chapters, as well as technical reports on research carried out in industry and educational activities. He is currently a Ph.D. student at the University of Baja California, in Mexicali, Baja California, Mexico with the subject of engineering and educative technology, analyzing improvement tools to avoid waste materials and economic losses, and increase the productivity and quality indices in this type of industry and any type of industries located in the city of Mexicali.

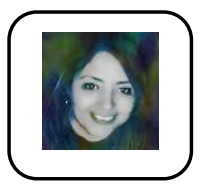

Olivia Yessenia Vargas Bernal, Is a professor in the Autonomous University of Baja California (UABC) and studied Industrial Engineering at the Faculty of Engineering Mexicali in UABC, and then studied a Master and $\mathrm{PhD}$ in Engineering by Engineering Institute (UABC). She has participated in publications optimization of processes, quality systems, and analysis of ergonomic methods. She has participated in national and international congresses. In 2014, she obtained the certification in the Standard of Competence EC0217 "Teaching Human Capital Training Courses in a Group Face-to-Face Way", by the Council for Standardization and Certification of Labor Competency (CONOCER). In 2020, she obtained virtual diplomate Teaching skills for distance education by Teacher Training and Evaluation Department Open and Distance Education Center (UABC). She has served as Head of the Quality Management System in local companies in the construction area. Since 2011, she has taught classes at the undergraduate and graduate level, as well as administrative activities at: University UNIVER (Now UNEA), University of the Valley of Mexico (UVM) as Academic Coordinator of Executive and Postgraduate Degree (Industrial Engineering and Systems, and Masters in Education), Sonora State University (UES), and at the UABC, being in the latter Head of the planning area and in charge of monitoring accreditations of the Faculty of Engineering Mexicali

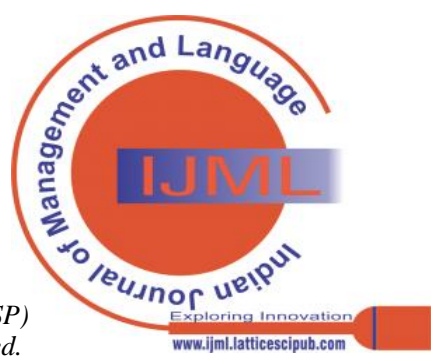

